\title{
Voxel anthropomorphic phantoms: review of models used for ionising radiation dosimetry
}

\author{
A. LEMOSQUET $^{1}$, L. DE CARLAN ${ }^{1}$, I. CLAIRAND $^{1}$
}

(Manuscript received 20 May 2003, accepted 22 August 2003)

\begin{abstract}
Computational anthropomorphic phantoms have been used since the 1970s for dosimetric calculations. Realistic geometries are required for this operation, resulting in the development of ever more accurate phantoms. Voxel phantoms, consisting of a set of small-volume elements, appeared towards the end of the $1980 \mathrm{~s}$, and significantly improved on the original mathematical models. Voxel phantoms are models of the human body, obtained using computed tomography (CT) or magnetic resonance images (MRI). These phantoms are an extremely accurate representation of the human anatomy. This article provides a review of the literature available on the development of these phantoms and their applications in ionising radiation dosimetry. The bibliographical study has shown that there is a wide range of phantoms, covering various characteristics of the general population in terms of sex, age or morphology, and that they are used in applications relating to all aspects of ionising radiation.
\end{abstract}

RÉSUMÉ Fantômes anthropomorphes voxélisés : revue des modèles appliqués à la dosimétrie des rayonnements ionisants.

Les fantômes anthropomorphes numériques sont utilisés depuis les années 1970 pour les calculs dosimétriques. Dans ce domaine, il est nécessaire de recréer des géométries réalistes, ce qui conduit à l'élaboration de fantômes de plus en plus précis. Les fantômes « voxélisés », constitués d'un ensemble de petits éléments de volume, sont apparus vers la fin des années 1980 et constituent une amélioration significative des modèles mathématiques déjà existants. Ce sont des modèles de corps humains obtenus à partir d'images tomodensitométriques (CT) ou de résonance magnétique (IRM). Ces fantômes constituent une représentation de l'anatomie humaine extrêmement précise. Cet article se propose de présenter une revue de la littérature en ce qui concerne le développement de tels fantômes et leurs applications dans le domaine de la dosimétrie des rayonnements ionisants. I'étude bibliographique effectuée montre que l'éventail des fantômes est large, couvrant diverses caractéristiques de la population générale en terme de sexe, d'âge, ou de morphologie, et que les applications portent sur tous les aspects des rayonnements ionisants.

\footnotetext{
I IRSN, Département de protection de la santé de l'homme ct de dosimétric, Service de dosimétrie, B.P. 17, 92262 Fontenayaux-Roses Cedcx, France.
} 


\section{Introduction}

Anthropomorphic phantoms have been commonly used for many years to provide the best representation of the human body in many situations, in a wide range of fields (physical measurements, ionising radiation dosimetry, car crash-tests, robotics, medicine, etc.). In the field of ionising radiation dosimetry, experiments made using physical phantoms cannot always reproduce all the configurations that are difficult, or even impossible, to reproduce in practice. For this reason, computational models have been developed for use alongside these physical phantoms. In particular, mathematical models, so-called because they are derived from mathematical equations, as developed mainly by the MIRD (Medical Internal Radiation Dose) Committee, have been used since the 1970 s for ionising radiation dosimetry (Fisher and Snyder, 1967; Snyder et al., 1969, 1975, 1978). These models have subsequently been modified, improved or adapted by several authors (Cristy, 1980; Cristy and Eckerman, 1987; Kramer et al., 1982; Kai, 1985; Kaul et al., 1987; Yamaguchi et al., 1987).

The human anatomy is, however, too complex to be modelled realistically using a limited set of equations. Moreover, the computing power available nowadays no longer restricts the representation of the person to simple geometric shapes. In the last few years, therefore, so-called voxel anthropomorphic phantoms, based on computed tomography (CT) or magnetic resonance images (MRI), have been created. These phantoms are known as "voxel" since they are made from a set of small volume elements (a voxel being in three-dimensional terms what a pixel is for a two-dimensional image). These phantoms give a much more realistic description of human anatomy than that of mathematical models since they are based on real anatomical data.

The first voxel phantoms were created in modeling laboratories from the middle of the 1980s. Nowadays, together with ever more powerful computer processing power and code, voxel phantoms are becoming increasingly important for ionising radiation dosimetry. This paper describes the voxel phantoms developed in the field of ionising radiation dosimetry, and particularly their specificity linked to this application. These phantoms are usually associated with a computer code, normally a Monte Carlo-type code.

\section{Voxel phantoms: review of the literature}

Voxel phantoms are created from the association of slices of the human body, using medical imaging, to give discrete volume elements of the anatomy, known as voxels. As an example, Figure 1 shows the external envelope of an anthropomorphic voxel phantom, the so-called modified Zubal phantom (Zubal et al., 1994) described in Section 2.1.3. 
VOXEL ANTHROPOMORPHIC PHANTOMS

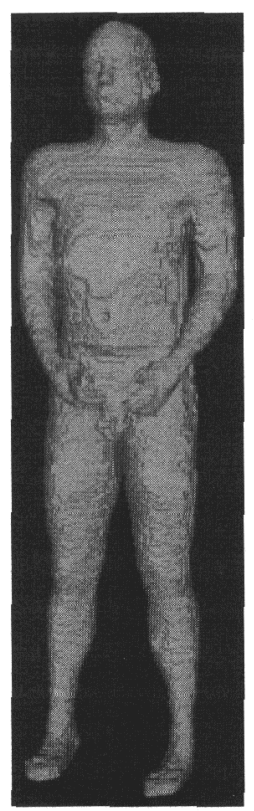

Figure 1 - External envelope of the "modified Zubal phantom" (Zubal et al., 1994).

Enveloppe externe du "fantôme de Zubal modifié » (Zubal et al., 1994).

The procedure for creating these phantoms includes a tissue and organ segmentation phase. Segmentation involves defining the boundaries of the contour of organ or tissue included in the phantom, as a function for example of the gray level and of the location of the voxels. Once it is created, a phantom may be associated with a Monte Carlo code, for any simulation or application the user requires.

In this review, phantoms are grouped by ethnic type and by project, and their applications are discussed as they arise. Tables I and II provide particular characteristics for each of the phantoms described.

\subsection{Caucasian type phantoms}

The Caucasian type (approximated to the populations of the white races) is the ethnic group that is most frequently modelled among voxel phantoms described in the literature. These are mainly adult phantoms, but there are also some paediatric phantoms available.

\subsubsection{Phantoms from the Visible Human Project}

The Visible Human Project was begun in 1986 by the National Library of Medicine (NLM) in the United States, as a result of the technological progress 
TABLE I

Characteristics of some anthropomorphic voxel phantoms applied to ionising radiation dosimetry.

Caractéristiques de quelques fantômes anthropomorphes voxélisés appliqués à la dosimétrie des rayonnements ionisants.

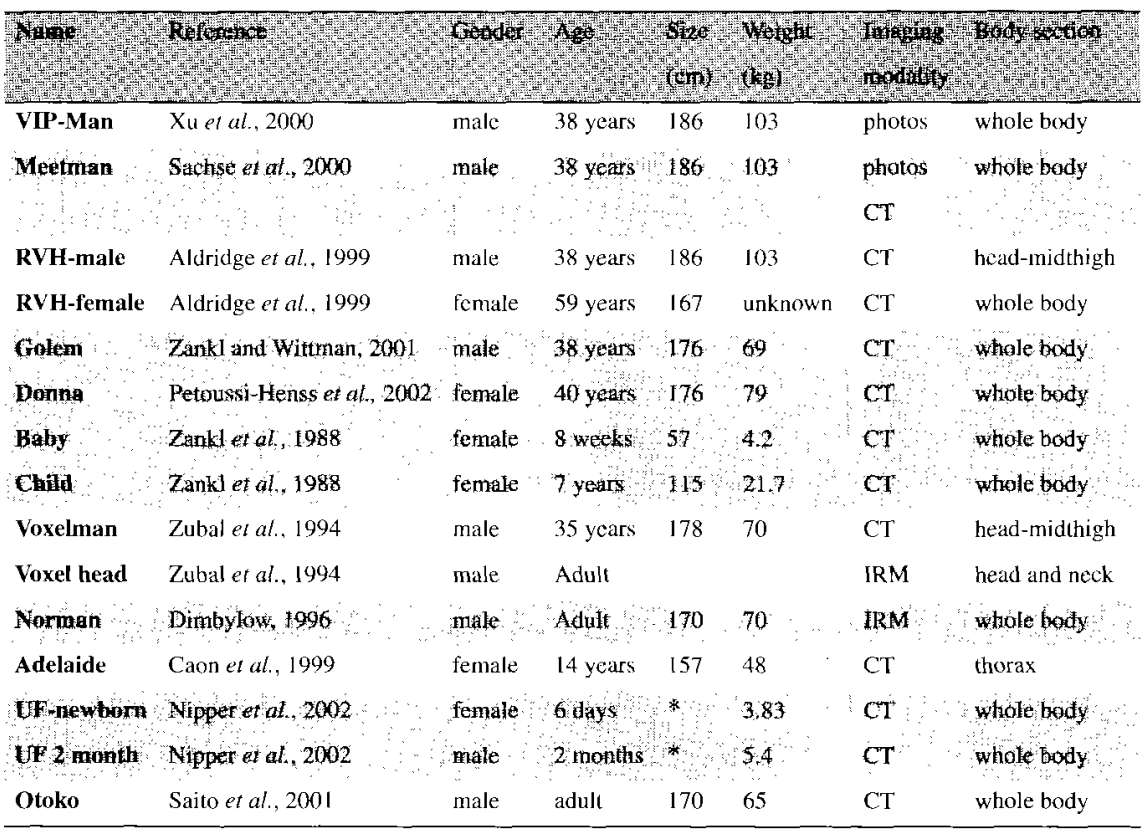

* not specified

made in the fields of imaging and biomedical research. The basis of the project was the creation of a library of images providing a complete representation of an adult man and woman. For this purpose, corpses (one male, one female), of healthy young adults were imaged using CT and MRI, and then the frozen bodies were cut, transversally, at intervals of one millimeter for the man and a third of a millimeter for the woman. Each of these sections was photographed in color. The Visible Human Project resulted in a very comprehensive anatomical description of the human body, with a Web-site devoted to the project as a whole (address: http://www.nlm.nih.gov/research/visible/). The age, size and weight of the man and the woman are shown in Table III. The size and weight of the two subjects studied are greater than those of the anthropomorphic standard, also shown in Table III, as determined by the International Commission for Radiological Protection (ICRP, 1975, 2002). The NLM gave Spitzer and Whitlock (1998) the task of preparing an anatomical atlas from the Visible Human Project data, which is available on interactive CD-Rom or on paper. The phantoms that were 
VOXEL ANTHROPOMORPHIC PHANTOMS

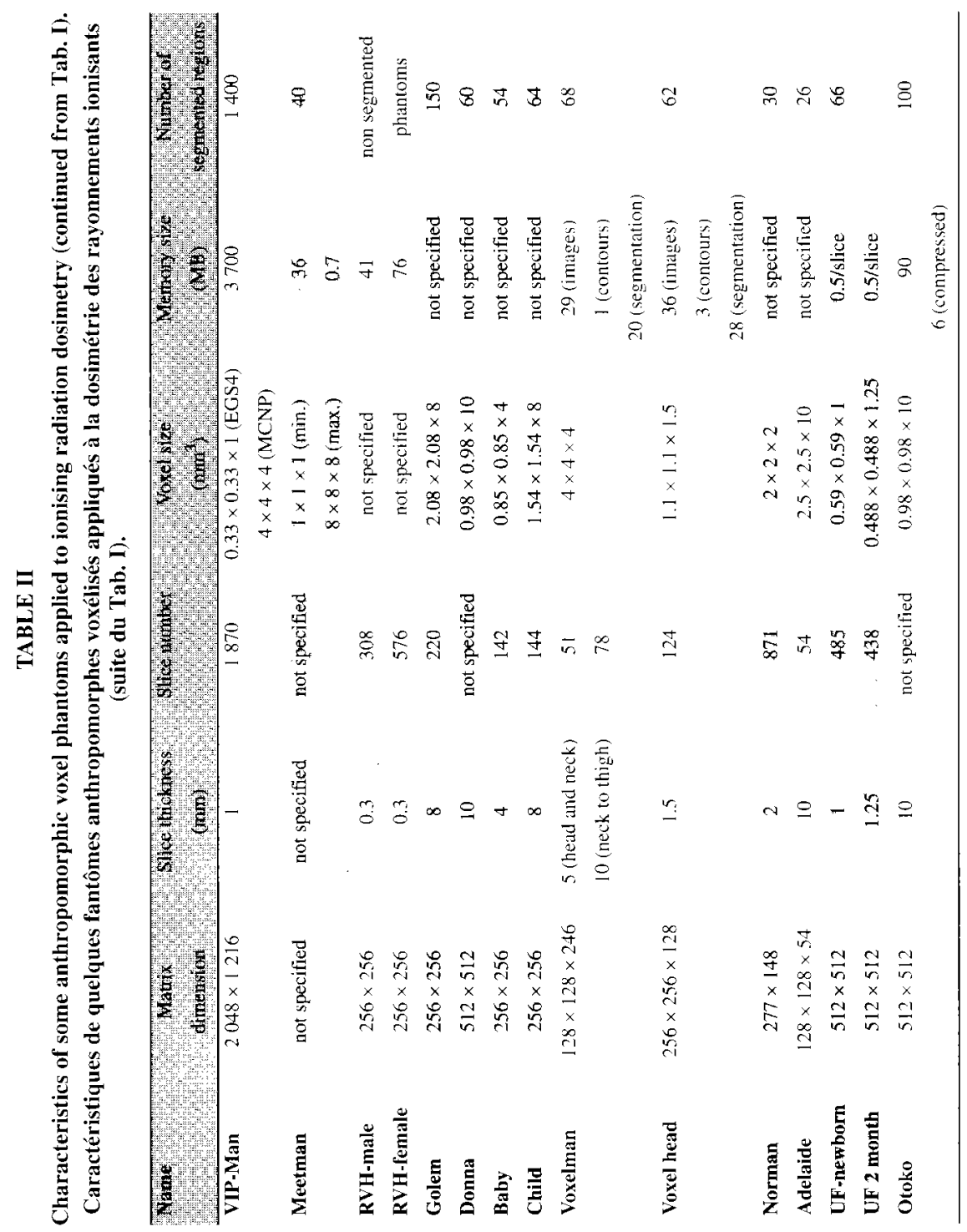


TABI.E III

Characteristics of the size and weight of the Reference Man and Woman and the Visible Human. Caractéristiques de taille et de poids de l'homme et la femme de référence et de Visible Human.

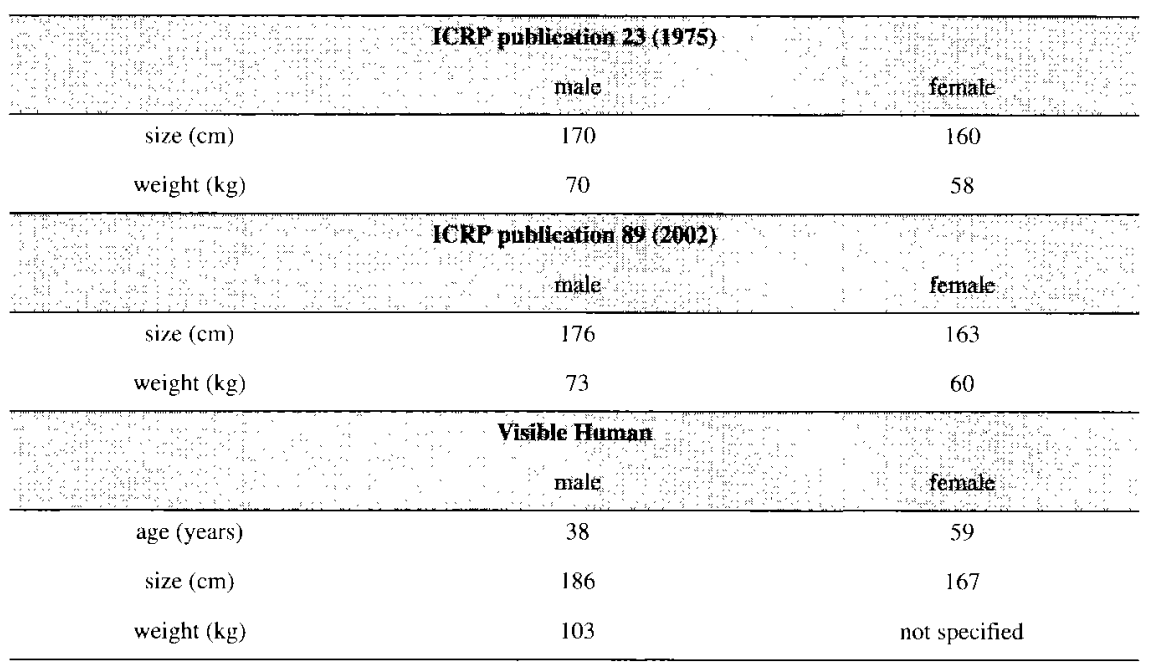

developed from this project include VIP-Man, Meetman and Reduced Visible Human. These are described in the following paragraphs.

VIP-Man. At the Rensselaer Polytechnic Institute, New York, Xu and his team (Xu et al., 2000) used the color photographic images from the Visible Human Project to segment a voxel phantom very precisely, and to carry out Monte Carlo simulations. The phantom developed from this work is called VIP-Man, VIsible Photographic-Man. According to the author, the only radiosensitive tissue not segmented in VIP-Man is the surface of the bones, since the spatial resolution required is too high for this structure. Figure 2, taken from Web-site http://www.rpi.edu/dept/radsafe/public_html/vipman/index.htm, shows a 3D view of the external envelope, of the skeleton and of some of VIP-Man's internal organs. A comparative study of the MCNP (Briesmeister, 2000) and EGS4 (Nelson et al., 1985) Monte Carlo codes was performed with $1 \mathrm{MeV}$ parallel photon beams, which showed remarkable consistency in the results, given the statistical uncertainties involved. Xu's team also used VIP-Man together with the Monte Carlo codes MCNP, EGS4 and MCNPX to perform important work calculating fluence-to-dose conversion coefficients for monoenergetic photons from $10 \mathrm{keV}$ to $10 \mathrm{MeV}$ (Chao et al., 2001 a), for neutrons up to $20 \mathrm{MeV}$ (Bozkurt et al., 2000), for monoenergetic neutron beams above $20 \mathrm{MeV}$ (Bozkurt et al., 2001 ), as well as for calculating specific absorbed fractions from electron emitters 


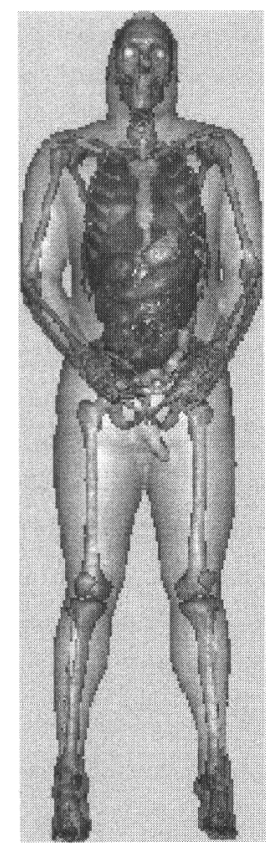

Figure 2-Three-dimensional view of the external envelope and skeleton of VIP-Man (http://www. rpi.edu/dept/radsafe/ public_html/vipman/index.htm).

Vue tridimensionnelle de l'enveloppe externe et du squelette de VIP-Man (http://www. rpi.edu/dept/radsafe/ public_html/vipman/index.htm).

distributed in various source organs and for various target organs (Chao and $\mathrm{Xu}$, 2001 ) over an energy range from $100 \mathrm{keV}$ to $4 \mathrm{MeV}$ and for calculating conversion coefficients for electrons from $100 \mathrm{keV}$ to $10 \mathrm{MeV}$ (Chao et al., 2001b).

Meetman. The MEETMAN (Models for Simulation of Electromagnetic, Elastomechanic and Thermic Behavior of MAN) project was developed at the Institute of Biomedical Engineering at Karlsruhe University, in Germany (Sachse et al., 2000). The project uses both photographic images from the Visible Human Project and CT images, since using both modalities allows adequate segmentation and classification of tissues. The applications cover more than just those relating to ionising radiation, particularly as regards the study of electromagnetic fields, thermal and elastomechanical properties of the body, and other medical applications, requiring in particular careful segmentation of the heart. Like VIPMan, Meetman also consists of a very realistic anatomical model of the human body. The commercial version of the project was developed in collaboration with the Virtual Reality company, and distributed under the name of Hugo. The phantom is available with different resolutions, the voxel size is between one and eight millimeters. There is a 3D display of Meetman on the Web-site http://wwwibt.etec.uni-karlsruhe.delforschung/meetman/meetman_en.htm. 
Reduced Visible Human. At the University of Wisconsin, in the United States, Aldridge (Aldridge et al., 1999) provides a standardized phantom for radiotherapy. The Visible Human Project corpses were imaged using a range of parameters (fields of view, slice thickness). For a fixed field of view and thickness of section, the CT images from the Visible Human Project were used to create a phantom with a resolution of $256 \times 256$ pixels for the $3 \mathrm{~mm}$ thick cross-sections. Two phantoms were reconstructed in this way: that of the man, from the head to mid-thigh, and that of the woman as a whole body. These phantoms are called Reduced Visible Human. The authors are now working on organising the MRI images of the Visible Human Project. The project is described on a Web-site, where the images can also be accessed: http://www-madrad.radiology.wisc.edu/vishum/index.html. These phantoms are used for research into intensity modulated radiotherapy (IMRT). It should be noted that these phantoms are not segmented: the electronic density of each voxel is used in calculations by the treatment planning system by converting the Hounsfield number (gray unit for CT images). The treatment planning system used (Pinnacle ${ }^{\circledR}$, Adac $^{\circledR}$ Company) includes an integration/convolution algorithm, the calculations performed are therefore not Monte Carlo-type.

\subsubsection{GSF phantoms}

After working on mathematical models derived from models developed by the MIRD committee, such as Adam and Eva (Kramer et al., 1982), the team responsible for medical physics in GSF - National Research Center for Environment and Health is now involved in developing a library of anthropomorphic voxel phantoms covering both sexes and a representative range of age, size and weight.

Golem. The Golem phantom is one of the first voxel phantoms from the GSF library (Zankl et al., 1995b; Zankl and Wittman, 2001). The patient that was used for the phantom was imaged from top to toe, on a CT scan system, because of a leukemia, but there are no obvious lesions on the images. The advantage Golem has over the Visible Human Project phantoms lies in the fact that its weight and size agree well with those of the Reference Man (ICRP, 1975, 2002).

Donna. The Donna phantom is a whole CT-based female human body (Petoussi-Henss et al., 2002). The size and weight properties of this phantom do not match those of the reference woman (ICRP, 1975, 2002). The number of segmented organs was fewer than for Golem. Moreover, even though the thickness of the section is greater, the resolution is better in the transverse matrix compared to that of Golem. 


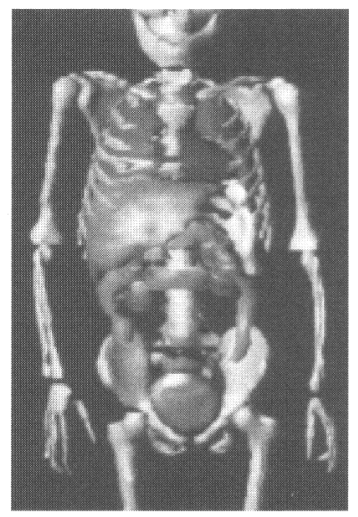

Figure 3-Trunk of the Child phantom: view of internal organs and skeleton (http://www.gsf.de/ institute/ISS/englisch/medphys/voxel.phtml).

Tronc du fantôme enfant: vue des organes internes et du squelette (http://www.gsf.de/ institute/ISS/englisch/medphys/voxel.phtml).

Baby and Child. The Baby and Child phantoms are among the rare paediatric phantoms described in the literature (Zankl et al., 1988). Baby was created from CT images of a deceased infant, and Child was taken from CT images of a sevenyear-old child (imaged because of a subsequent total body irradiation). Seven different media are simulated according to their elemental composition: soft tissue, lung, bone, air, bone marrow, skin and muscle. For Child, the authors consider that the child is a little small for its age, and that it better represents a child of between 5 and 7 years of age.

Figure 3, from Web-site http://www.gsf.de/institute/ISS/englisch/medphys/ voxel.phtml, represents the trunk (internal organs and skeleton) of the Child phantom. This site also gives a representation of the Golem and Donna phantoms.

There are other phantoms in the GSF library, but only partial information about these has so far been published. Helga (head to mid-thigh) and Irene (whole body) are two female adult phantoms and Frank (head and trunk) and Visible Human (head to knee) are two male adult phantoms (Petoussi-Henss et al., 2002; Zankl et al., 2002). A model of the female digestive system has also been voxelized, as an important area from a dosimetric point of view, particularly for internal exposure. The GSF team worked on calculations of the specific absorbed fractions (SAF), as a prerequisite for calculating the absorbed dose in internal dosimetry 
(Petoussi-Henss and Zankl, 1998). Calculations were made for monoenergetic photon sources, on the following phantoms: Baby, Child, Golem as well as on the phantom developed by Zubal (Zubal et al., 1994). These SAFs are used to calculate the absorbed dose, the effective dose (Petoussi-Henss and Zankl, 1998; Smith et al., 2000) and the committed dose (only on Golem) (Smith et al., 2001) for various radionuclides. As expected, the studies show that there is a greater degree of realism in shape and location of organs in anthropomorphic voxel phantoms than in mathematical models. Variations in SAFs for monoenergetic photons were observed between voxel phantoms and the reference mathematical phantoms. These variations arise, on the one hand, from differences in stature between the individuals from whom the voxel phantoms are derived and the mathematical models used, built from average bodily dimensions, and on the other, from differences in shape and location of organs. The authors of this work therefore recommend the use of voxel phantoms the size of whose organs is representative of the population under study, since the SAF is very dependent on the mass of the organs. For external dosimetry, the GSF team worked on establishing air kerma-to-dose conversion coefficients for exposure to photon beams in Baby and Child (especially for radiology examinations), Donna, Golem and Visible Human (Veit and Zankl, 1992, 1993; Zankl et al., 1988, 1995a, 1995b, 2002). The results were compared to those from the reference mathematical models from the new-born child, from the 10-year-old child (Cristy and Eckerman, 1987), from Eva and from Adam.

\subsubsection{Zubal's phantoms}

At Yale University, in the United States, the Zubal team uses voxel phantoms for Monte Carlo simulations of the internal distribution of radiopharmaceuticals (Zubal et al., 1990; Zubal and Harrell, 1992).

A whole body phantom (actually from head to mid-thigh) built from CT images, as well as a head phantom, built from MRI pictures, are described in the literature (Zubal et al., 1994, 1995). These phantoms can be downloaded from http://noodle.med.yale.edu/zubal/. This site also carries two versions of the whole body phantom, onto which the arms and legs from the Visible Human have been added, with the arms folded to the level of the abdomen, or with the arms lying alongside the body.

Whole body phantom (Voxelman). The size and weight characteristics of Zubal's whole body phantom are reasonably consistent with those of the reference man (ICRP, 1975, 2002) but the resolution is not as good as that of the GSF phantoms. 
Zubal's whole body phantom was used by Yoriyaz (Yoriyaz and dos Santos, 2000; Yoriyaz et al., 2001) in association with the MCNP code. This phantom has been used to calculate absorbed fractions (AF) and SAFs. The authors' conclusions show that the results achieved with the voxel phantoms normally agree with the reference values obtained with the mathematical models. Nonetheless, in some cases there are significant differences, which could be caused by difference in organ mass, and organs sometimes overlap in voxel phantoms, which does not occur with mathematical models. The main area of application for the Yoriyaz work is patient-specific dosimetry in radioimmunotherapy: this allows patient treatment plans to be improved by using phantoms based on images of the subject itself. Moreover, a publication by Sandborg (Sandborg et al., 2000) describes a study on the use of Zubal's whole body phantom in optimising radiological examinations of the chest and the lumbar vertebrae.

CT images of the head alone have also been used by Loureiro (Loureiro et al., 2002) who created MCvoxEL, a phantom with the same characteristics as the original images (resolution of $512 \times 512 \times 55$ voxels, voxel size $0.5 \times 0.5 \times$ $5 \mathrm{~mm}^{3}$ ). This phantom only has about twenty segmented structures since the author was not trying to identify a large number of organs, but to segment important tissues for radiation protection purposes.

Kramer used the Zubal phantom, modified with the arms along the body, to calculate conversion factors for the air kerma to the equivalent dose for photon beams with the Monte Carlo code EGS4. The phantom was modified so that the mass of its organs corresponds to the reference values defined in ICRP publications: the modified phantom is called VOXMAN for correspondence with ICRP publication 23 (Kramer et al., 2002; ICRP, 1975, 1995) and MAX (Male Adult voXel) for correspondence with ICRP publication 89 (Kramer et al., 2003; ICRP, 2002).

Head phantom. The Zubal head phantom is shown in Tables I and II as Voxel head. Evans (Evans et al., 2001) applied the Zubal phantom head for cases of external irradiation with neutron beams, in the field of neutron therapy research. The phantom was modified before beginning the calculations: the 62 structures were reduced to 39 , resolution went from $256 \times 256 \times 128$ voxels to $85 \times 108 \times$ 120 voxels and voxel dimensions were $2.2 \times 2.2 \times 1.4 \mathrm{~mm}^{3}$. The absorbed dose was calculated in the structures concerned, including the pituitary gland, selected because it is the smallest critical structure. The results were reliable for the largest structures in the brain (frontal lobes, white matter, corpus callosum, etc.) and dose uncertainties remain with acceptable limits for the smallest structures, such as the pituitary gland or the optical nerves $(<5 \%)$. 


\subsubsection{NRPB (National Radiological Protection Board) phantom}

Norman. The National Radiological Protection Board (NRPB) is a British radiological protection agency. Norman, the phantom created by Dimbylow (Dimbylow, 1996) is one of the only whole body phantoms created from MRI images, which has incidentally caused problems in segmentation of the bones. Originally the phantom was created to study electromagnetic fields (Dimbylow, 2000, 2002). The phantom's measurements were close to those of the Reference Man and the author modified the size and weight of the model to the reference values given by the ICRP (ICRP, 1975, 1993), hence the phantom's name, meaning NORmalised MAN.

Jones used the Norman phantom in ionising radiation dosimetry to calculate effective doses for external dosimetry (Jones, 1997), and SAFs for internal dosimetry (Jones, 1998). The results were compared to those obtained on the MIRD model (Snyder et al., 1969, 1975, 1978), as well as those from Golem (GSF), in calculating effective doses for external irradiation, and to those obtained from the voxel version of the MIRD model for calculating SAFs. Significant variations were detected in the SAFs values between mathematical models and voxel phantoms, attributable to anatomical differences between the two types of phantom rather than to the calculation itself, since there was considerable agreement between the results of the MIRD mathematical version and its voxel equivalent (Jones, 1998).

Hunt used Norman for in vivo measurements (Hunt et al., 1998, 1999, 2000). A simulation program using Monte Carlo methods was carried out for this, specifically for calibrating in vivo measurements (measuring ${ }^{137} \mathrm{Cs},{ }^{241} \mathrm{Am}$ and uranium contamination).

\subsubsection{LLNL (Laurence Livermore National Laboratory) phantoms}

In the second half of the 90s, the Hickman team (Hickman and Firpo, 1997) at the Lawrence Livermore National Laboratory (LLNL), United States, was researching into a method for calibrating in vivo measurement systems using MRI. The anatomical information is used to model a phantom, and simulations are then conducted to calculate calibration factors specific to an individual. The MRIPP (Magnetic Resonance Imaging Photon Phantom) software package developed, writes an input file in MCNP code format, depending on the required geometry. The information contained in the mentioned document indicates that the database includes 33 phantoms. The bodies may be placed in a range of positions (standing, laid down, seated with legs straight, seated with legs bent), with orientations simulated by moving different parts of the MRIs. The initial resolution of the 
images is reduced to compensate for the limited number of cells, 100000 in MCNP, by averaging the properties of the adjacent voxels. The segmentation technique does not involve precise determination of the outline of organs or tissues. Each voxel is in fact a cell, and the composition of each one is determined by its location with respect to the other voxels (Mallett et al., 1995), only distinguishing between air, bone and soft tissue.

\subsubsection{IRSN (Institut de radioprotection et de sûreté nucléaire) interface for fast construction of voxel phantoms}

At the French Institute for Radiation Protection and Nuclear Safety (IRSN), the in vivo measurement group at the Internal Dose Evaluation and Modeling Laboratory (LEMDI) is developing voxel phantoms, and the automated writing of these phantoms to input files in MCNP code. Data processing, before and after the calculation, uses a graphical user interface (GUI) called "Anthropo" (Franck et al., 2001; Borissov et al., 2002). This program enables calibration of in vivo measurement systems, using individual-specific data (CT or MRI pictures from the person being measured), a particularly important procedure for measuring actinides (low-energy photons emission), wound contamination, or for heterogeneous contamination. The tool is compatible with a range of systems (MS Windows ${ }^{\circledR}$, Unix) and was developed with the PV-Wave ${ }^{\circledR}$ data analysis software. By using CT or MRI pictures of the subject as input, together with the choice of source (point or diffuse, activity), and the geometry and position of the detector, the "Anthropo" program is specially formatted for MCNP to allow photon spectra simulation in the detectors used for gamma spectrometry and in vivo measurement systems.

\subsubsection{The ADELAIDE phantom}

Adelaide is a paediatric thoracic phantom (female) created at the University of Adelaide in Australia (Caon et al., 1999, 2000). The characteristics of this phantom are shown in Tables I and II. The authors do not know the medical reasons for imaging the patient but there is no anomaly shown on the images. The size and weight characteristics of this phantom are slightly less than those of the average 14-year-old Australian adolescent female, which would be $50.4 \mathrm{~kg}$ and $159.7 \mathrm{~cm}$ (Hitchcock et al., 1986). Modifying the size of all the voxels by plus or minus 5\%, the phantom's morphology may be adapted to match the anatomy of a child of 11,12 or 16 years of age. This phantom is used in applications such as calculation of effective doses received by adolescents during CT scan investigations of the chest, the abdomen or the whole torso. 


\subsubsection{The University of Florida phantoms}

Recently, two paediatric whole body voxel phantoms have been constructed at the University of Florida (Nipper et al., 2002). The whole procedure of images acquisition and segmentation of these phantoms is comprehensively detailed in the article by Nipper. The models aim at performing simulations of diagnostic and interventional X-ray examinations (Staton et al., 2003), coupling the phantoms to the EGS Monte Carlo code.

UF-newborn. It was created from CT images of a 6-day-old female cadaver imaged within 24 hours of death. Two additional datasets were used for insertion of the lungs (from a one-month-old patient with interstitial disease) and the adrenal glands (from a two-month-old patient). The completed model contains 66 segmented regions. The phantom was used to perform calculations of organ dose due to radiological examinations (Staton et al., 2003), and to make comparisons with the mathematical newborn model (Cristy and Eckerman, 1987).

UF 2 month. It was created from CT images of a 6-month-old male cadaver imaged within 6 hours of death. The model applies to a two-month-old, for the patient had a low weight at the time of death $(5.4 \mathrm{~kg}$, the patient was born almost three months premature). The completed model contains 67 segmented regions. The phantom represents a model of a critical ill child with tissue oedema. It is representative of a subpopulation that would experience a much larger number of diagnostic or interventional X-ray examination.

\subsection{Asiatic type phantoms}

There is only one Asiatic type phantom described in the literature. It is Japanese, and called Otoko.

Otoko. The standard adult male Japanese weighs $60 \mathrm{~kg}$, and is $170 \mathrm{~cm}$ tall (Tanaka et al., 1989), characteristics closely matched by Otoko (cf. Tab. I). The subject imaged to create the phantom has a spleen half the size of the average (Saito et al., 2001), showing that if a subject has size and weight characteristics matching those of the reference, this does not necessarily apply to all its organs. The simulations performed on this phantom brought to calculate doses to organs for external exposure to photons and electrons.

The doses calculated were compared to the results from the mathematical model Adam, as well as those from the voxel phantom Golem, both developed at GSF. Significant discrepancies were noted in some cases. These discrepancies are explained by the difference in stature between the Caucasian and Asiatic types, 
the difference in modeling (mathematical or voxelised), the particular features of the individual's anatomy compared to the standard, and the diversity in the calculation methods for particle transport. The differences are more noticeable at low energies and for deep-lying organs, because of photon attenuation, which is affected by position.

\section{Discussion}

In the field of ionising radiation dosimetry, calculations based on computational anthropomorphic models are often preferable to direct measurements on physical phantoms, since they allow dosimetric quantities to be estimated for configurations that are difficult, or even impossible, to reproduce in practice.

The first type used, anthropomorphic mathematical models, were by definition a much simpler representation of the human body than the voxel anthropomorphic models based on CT or MRI images. The level of realism achieved with the development of voxel phantoms means that dosimetric estimates can be refined, particularly as regards energy deposits in localised areas of the human body, for both internal and external dosimetry, and for low-energy particles which travel only a short distance through the material. A phantom library, or construction of voxel phantoms based on reference anatomical data, is considered necessary for applications other than personal dosimetry. In particular, one of the interesting features of voxel phantoms is the possibility of changing their size, thus simulating individuals of different builds. The dimensions may be modified and adapted independently in each of the three axes in space (Veit and Zankl, 1992, 1993; Caon et al., 2000). The scale factor must nonetheless remain within a reasonable range, without any major errors being introduced into the anatomical proportions of the organs (Phipps and Zankl, 2001). The calculations with voxel phantoms also allows dose-volume histograms (DVH) to be calculated, providing a graphical way of condensing and reading the dose distribution in an anatomical structure.

What is gained in the level of realism in the anatomy of voxel phantoms does however have some drawbacks. The surface of the organs has a crenated appearance because of the voxelization. This is all the more apparent the smaller the organs are with respect to the size of the voxel. This may lead to errors in calculating energy deposits in these areas, especially for hollow organs such as the bladder or the stomach, if the resolution is not suitable. Another limitation of voxel phantoms relates to image acquisition: patients passing through the ring of a CT scan system or MRI are normally in the supine position, which causes the abdominal organs to shift towards the upper part of the body, and compresses the lungs. This is not always the position in which simulations are performed (for accident reconstruction, or for radiology for example). 
The procedure for segmenting CT or MRI slices requires great care, which even though it may sometimes be semi-automated for contrasted structures (bones, lungs), very often requires intervention by an operator. Segmentation is also made more difficult the more organs or regions there are to be separated.

The process of implementation of computational tools based on voxel phantoms has to comprise a validation step. In this aim, several teams converted mathematical models and physical phantoms into voxel phantoms. In 1985, Yamaguchi (National Institute of Radiological Sciences, Japan) converted the 1969 Snyder model into a voxel model (Yamaguchi et al., 1985). This was the precursor of the more realistic models based on CT or MRI pictures. In the 90s, Akabani (Akabani, 1995) produced voxel versions of Cristy and Eckerman's series of models (Cristy and Eckerman, 1987) including the models of a newborn, 1-year-old, 5-year-old, 10-year-old, 15-year-old, and an adult male. At GSF, two physical phantoms have been voxelized (Petoussi-Henss et al., 2002). The studies performed involved comparing doses measured by thermoluminescent dosimeters, and those calculated using a Monte Carlo type code belonging to GSF with an Alderson-Rando torso phantom, on whole body configurations (CT irradiation and ${ }^{60} \mathrm{Co}$ irradiations) (Veit et al., 1992). The validation steps set out on certain computational tools are quite encouraging (Veit et al., 1992; Borissov et al., 2002).

\section{Conclusion}

This article has reviewed the existing voxel anthropomorphic phantoms. Technological advances in medical imaging and computer processing power have enabled the use of precise anatomical data of real people, leading to the development of voxel phantoms. We have seen that there is now a wide range of such phantoms available for ionising radiation dose measurement, calibration of measurement systems or evaluation and processing of images. About ten whole body adults voxel phantoms, one head voxel phantom and five paediatric voxel phantoms have been listed. Among them, some are available to the scientific community. Zubal's phantoms are free, as well as the reduced data sets of the Visible Human Project. Meetman also is available, against payment. Their characteristics are determined by the use made of them (individual or standard phantom, resolution, segmentation, etc.). For example, a reference individual is required for application of directives and regulations concerning the protection of the health of workers and public against the dangers arising from ionising radiation, e.g. conversion coefficients for external dosimetry calculated by a range of authors are given in ICRP publication 74 (ICRP, 1996). Conversely, for a customised dosimetry or calibration, the personal phantom for the individual itself has to be recreated. These elements should be kept in mind when creating or using a model. 
Voxel phantoms are more realistic as regards shape, size and location of organs with respect to mathematical phantoms. The differences with MIRD-type mathematical phantoms used in the calculations mainly relate to low energies, and deep organs. The precise position of the organs is very important for electrons and other charged particles, since they have a short path length with respect to the sizes of the organs. Up to now, most calculations have been performed on photon beams, and there are few calculations available on sources of electrons, protons or neutrons, with which radiation protection is also concerned. They offer a new way forward for dosimetrists and they will lead to more accurate and reliable dose assessment. The use of voxel phantoms has only just begun, and they will certainly be of interest for a long time.

Acknowledgements. This work is funded under the terms of an agreement between the IRSN and EDF.

\section{REFERENCES}

Akabani G. (1995) Development and implementation of digitized phantoms for use in nuclear medicine procedures. In: Voxel phantom development, 6 and 7 July 1995, Chilton, UK (P.J. Dimbylow, Ed) pp. 112-120.

Aldridge J.S., Rechwerdt P.J., Rockie T.R. (1999) A proposal for a standard electronic anthropomorphic phantom for radiotherapy, Med. Phys. 26, 1901-1903.

Borissov N., Franck D., de Carlan L., Laval L. (2002) A new Graphical User Interface for fast construction of computation phantoms and MCNP calculations: application to calibration of in vivo measurement system, Health Phys. 83, 272-279.

Bozkurt A., Chao T.C., Xu X.G. (2000) Fluence-to-dose conversion coefficients from monoenergetic neutrons below $20 \mathrm{MeV}$ based on the VIP-Man anatomical model, Phys. Med. Biol. 45, 3059 3079.

Bozkurt A., Chao T.C., Xu X.G. (2001) Fluence-to-dose conversion coefficients based on the VIPMAN anatomical model and MCNPX code for monoenergetic neutrons above $20 \mathrm{MeV}$, Health Phys. 81, 184-202.

Briesmeister J.F. (2000) MCNPTM - A general Monte Carlo N-particle transport code, version 4c. LANL Memorandum. Los Alamos National Laboratory, LA-13709-M.

Caon M., Bibbo G., Pattison J. (1999) An EGS4-ready tomographic computational model of a fourteen year-old female torso for calculating organ doses from CT examinations, Phys. Med. Biol. 44, 2213-2225.

Caon M., Bibbo G., Pattison J. (2000) Monte Carlo calculated effective dose to teenage girls from CT examinations, Radiat. Prot. Dos. 90, 445-448.

Chao T.C., Xu X.G. (2001) Specific absorbed fractions from the image-based VIP-Man body model and EGS4-VLSI Monte Carlo code: internal electron emitters, Phys. Med. Biol. 46, 901-927.

Chao T.C., Bozkurt A., Xu X.G. (2001a) Conversion coefficients based on the VIP-MAN anatomical model and EGS4-VLSI code for external monoenergetic photons from $10 \mathrm{keV}$ to $10 \mathrm{MeV}$, Health Phys. 81, 163-183.

Chao T.C., Bozkurt A., Xu X.G. (200lb) Organ dose conversion coefficients for 0.1-10 MeV electrons calculated for the VIP-Man tomographic model, Health Phys. 81, 203-215. 


\section{A. LEMOSQUET et al.}

Cristy M. (1980) Mathematical phantoms representing children of various ages for use of estimates of internal dose. ORNL/NUREG/TM-367.

Cristy M., Eckerman K.F. (1987) Specific absorbed fractions of energy at various ages from internal photon sources. ORNL/TM-8381.

Dimbylow P.J. (1996) The development of realistic voxel phantoms for electromagnetic field dosimetry. NRPB (National Radiological Protection Board), Chilton, UK, pp. 1-7.

Dimbylow P.J. (2000) Current densities in a $2 \mathrm{~mm}$ resolution anatomically realistic model of the body induced by low frequency electric fields, Phys. Med. Biol. 45, 1013-1022.

Dimbylow P.J. (2002) Fine resolution calculations of SAR in the human body for frequencies up to 3 GHz, Phys. Med. Biol. 47, 2835-2846.

Evans J.F., Blue T.E., Gupta N. (2001) Absorbed dose estimates to structures of the brain and head using a high-resolution voxel-based head phantom, Med. Phys. 28, 780-786.

Fisher H.L., Snyder W.S. (1967) Distribution of dose in the body from a source of gamma rays distributed uniformly in an organ. ORNL-4168 245-257.

Franck D., Laval L., Borissov N., Guillierme P., Bordy J.M. (2001) Development of voxelised numerical phantoms using MCNP Monte Carlo code: application to in vivo measurement, Radioprotection 36, 77-86.

Hickman D.P., Firpo M. (1997) Magnetic Resonance Image phantom. CA: Lawrence Livermore National Laboratory.

Hitchcock N.E., Maller R.A., Gilmour A.I. (1986) Body size of young Australians aged five to 16 years, Med. J. Aust. 145, 368-372.

Hunt J.G., Dantas B.M., Lucena E. (1998) Calibration of an in vivo measurement system using a voxel phantom, Radiat. Prot. Dos. 79, 425-427.

Hunt J.G., Malatova 1., Foltdnova S. (1999) Calculation and measurement of calibration factors for bone surface seeking low energy gamma emitters and determination of ${ }^{241}$ Am activity in a real case of internal contamination, Radiat. Prot. Dos. 82, 215-218.

Hunt J.G., Malatova I., Foltanova S., Dantas B.M. (2000) Calibration of in vivo measurement systems using a voxel phantom and the Monte Carlo technique, Radiat. Prot. Dos. 89, 283-286.

ICRP publication 23 (1975) Reference Man: Anatomical, Physiological and Metabolic Characterisation. Pergamon Press, Oxford.

ICRP publication 66 (1993) Respiratory tract model for radiological protection, Ann. ICRP 24(1-3).

ICRP publication 70 (1995) Basic anatomical and physiological data for use in radiological protection: the skeleton, Ann. ICRP 25(2).

ICRP publication 74 (1996) Conversion coefficients for use in radiological protection against external radiation, Ann. ICRP 26(3-4).

ICRP publication 89 (2002) Basic anatomical and physiological data for use in radiological protection: reference values, Ann. ICRP 32(3-4).

Jones D.G. (1997) A realistic anthropomorphic phantom for calculating organ doses arising from external photon irradiation, Radiat. Prot. Dos. 72, 21-29.

Jones D.G. (1998) A realistic anthropomorphic phantom for calculating specific absorbed fractions of energy deposited from internal gamma emitters, Radiat. Prot. Dos. 79, 411-414.

Kai M. (1985) Estimation of embryonic and fetal doses from accidentally released radioactive plumes, Radiat. Prot. Dos. 11, 91.

Kaul D.C., Egbert S.D., Otis M.D., Kuhn T., Kerr G.D., Eckerman K.F., Cristy M., Maruyama T., Ryman J.C., Tang J.S. (1987) Organ dosimetry. In: US-Japan reasiessment of atomic bomb 


\section{VOXEL ANTHROPOMORPHIC PHANTOMS}

radiation dosimetry in Hiroshima and Nagasaki (W.C. Roesch, Ed.), p.306. Radiation Effects Research Foundation, Hiroshima, Japan.

Kramer R., Zankl M., Williams G., Drexler G. (1982) The calculation of dose from external photon exposures using reference human phantoms and Monte Carlo methods: part I, The male (Adam) and female (Eva) adult mathematical phantoms, GSF-report S-885.

Kramer R., Vieira J.W., Lima F.R., Fuclle D. (20)2) An EGS4 based Monte Carlo code for the calculation of organ equivalent dose to a modificd Yale voxel phantom, Cell Mol. Biol. 48, 465473.

Kramer R., Vieira J.W., Khoury H.J., Lima F.R., Fuelle D. (2003) All about MAX: a male adult voxel phantom for Monte Carlo calculations in radiation protection, Phys. Med. Biol. 48, 1239-1262.

Loureiro E.C., Lima F.R., Stabin M.G. (2002) A voxel-based head-and-neck phantom builı from tomographic colored images, Cell Mol. Biol. 48, 461-464.

Mallett M.W., Hickman D.P., Knuchen D.A., Poston J.W. (1995) Development of a method for calibrating in vivo measurement systems using magnetic resonancc, Health Phys. 68, 773-785.

Nelson W.R., Hirayama H., Rogers D.W.O. (1985) The EGS4 code system, Stanford Linear Accelerator Center, Stanford University, Stanford, California, SLAC-265.

Nipper J.C., Williams J.L., Bolch W.E. (2002) Creation of two tomographic voxel models of paediatric patients in the first year of life, Phys. Med. Biol. 47, 3143-3164

Petoussi-Henss N., Zankl M. (1998) Voxel anthropomorphic models as a tool for internal dosimetry, Radiat. Prot. Dos. 79, 415-418.

Petoussi-Henss N., Zankl M., Fill U., Regulla D. (2002) The GSF family of voxel phantoms, Phys. Med. Biol. 47, 89-106.

Phipps A., Zankl M. (2001) New Computer Phantoms and their usc in Internal Dosimetry, NRPB Radiol. Prot. Bull. 232, 24-27.

Sachse F.B., Werner C.D., Meyer-Waarden K., Dössel O. (2000) Development of a human body model for numerical calculation of electrical fields, Comput. Med Imag. Graph. 24, 165-171.

Saito K., Witlman A., Koga S., Ida Y., Kamei T., Funabiki J., Zankl M. (2001) Construction of a computed tomographic phantom for a Japanese male adult and dose calculation system, Radiat. Environ. Biophys. 40, 69-76.

Sandborg M., Mc Vey G., Dance D.R., Persliden J., Alm Carlsson G. (2000) A voxel phantom based Monte Carlo computer program for optimisation of chest and lumbar spine X-ray imaging systems, Radiat. Prot. Dos. 90, 105-108.

Smith T., Petoussi-Henss N., Zankl M. (2000) Comparison of internal radiation doses estimated by MIRD and voxel techniques for a "family" of phantoms, Eur. J. Nucl. Med. 27, 1387-1398.

Smith T.J., Phipps A.W., Petoussi-Henss N., Zankl M. (2001) Impact on internal doses of photons SAFs derived with the GSF adult male voxel phantom, Health Phys. 80, 477-485.

Snyder W.S., Ford M.R., Warner G.G., Fisher H.L. (1969) Estimates of absorbed fractions for monoenergetic photon sources uniformly distributed in various organs of a heterogeneous phantom. Journal of Nuclear Medicine, Medical Internal Radiation Dose Committee Pamphlet $\mathrm{n}^{\circ} 5$, Supplement $\mathrm{n}^{\circ} 3$

Snyder W.S., Ford M.R., Warner G.G., Watson S.B. (1975) 'S', absorbed dose per unit cumulated activity for selected radionuclides and organs, New York, the Society of Nuclear Medicine, Medical Internal Radiation Dose Committee Pamphlet $n^{\circ} 11$.

Snyder W.S., Ford M.R., Warner G.G., Fisher H.L. (1978) Estimates of absorbed fractions for monoenergetic photon sources uniformly distributed in various organs of a heterogeneous phantom. New York: the Society of Nuclear Medicine, Medical Internal Radiation Dose Committee Pamphlet $n^{\circ} 5$, Revised 
Spitzer V.M., Whitlock D.G. (1998) Atlas of the visible human male. Jones and Bartlett Publishers, Sudbury, MA.

Staton R.J., Pazik F.D., Nipper J.C., Williams J.L., Bolch W.E. (2003) A comparison of newborn stylized and tomographic models for dose assessment in paediatric radiology, Phys. Med. Biol. 48, 805-820.

Tanaka G., Nakahara Y., Nakajima Y. (1989) Japanese reference man 1988-IV. Studies on the weight and sizc of internal organs of normal Japanese, Nippon Acta Radiol. 49, 344.

Veit R., Zankl M. (1992) Influence of patient size on organ doses in diagnostic radiology, Radiat. Prot. Dos. 43, 241-243.

Veit R., Zankl M. (1993) Variation of Organ Doses in Paediatric Radiology due to Paticnt Diameter, Calculated with Phantoms of Varying Voxel Size., Radiat. Prot. Dos. 49, 353.

Veit R., Panzer W., Zankl M., Scheurer C. (1992) Vergleich berechneter und gemessener Dosen an einem anthropomorphen Phantom, Z. Med. Phys. 2, 123-126.

Xu X.G., Chao T.C., Bozkurt A. (2000) VIP-Man: an image-based whole-body adult male model constructed from color photographs of the visible human project for multi-particle Monte Carlo calculations, Health Phys. 78, 476-486.

Yamaguchi H., Hongo S., Takeshita H. (1985) Three-dimensional digital representation of human phantom for organ dose calculation, in: XIV International Conference on Medical and Biological Engineering and VII International Conference on Medical Physics, 6 and 7 July 1985, Espoo, Finland.

Yamaguchi Y., Togawa O., Honma T. (1987) The VADMAP code to calculate the SAF of Photon: code description and the Performance, JAERI-M 87-186.

Yoriyaz H., dos Santos A. (2000) Absorbed fractions in a voxel-based phantom calculated with the MCNP-4B code, Med. Phys. 27, 1555-1567.

Yoriyaz H., Stabin M.G., dos Santos A. (2001) Monte Carlo MCNP-4B-based absorbed dose distribution estimates for patient-specific dosimetry, J. Nucl. Med. 42, 662-669.

Zankl M., Wittman A. (2001) The adult male voxel "Golem" segmented from whole body CT patient data, Radiat. Environ. Biophys. 27, 153-164.

Zankl M., Veit R., Williams G., Schneider K., Fendel H., Petoussi N., Drexler G. (1988) The construction of computer tomographic phantoms and their application in radiology and radiation protection, Radiat. Environ. Biophys. 27, 153-164.

Zankl M., Panzer W., Petoussi-Henss N., Drexler G. (1995a) Organ doses for children from computed tomographic examinations, Radiat. Prot. Dos. 57, 393-396.

Zankl M., Petoussi N., Wittman A. (1995b) The GSF voxel phantom and their application in radiology and radiation protection, in: Voxel phantom development, 6 and 7 July 1995, Chilton, UK (P.J. Dimbylow, Ed) pp. 98-104.

Zankl M., Fill U., Petoussi-Henss N., Regulla D. (2002) Organ dose conversion coefficients for external photon irradiation of male and female voxel models, Phys. Med. Biol. 47, 2367-2385.

Zubal I.G., Harrell C.R. (1992) Voxel based Monte Carlo Calculations of Nuclear Medicine Images and Applied Variance Reduction Techniques, Imag. Vis. Comput. 10, 342-348.

Zubal I.G., Harrell C.R., Esser P.D. (1990) Monte Carlo determination of emerging energy spectra for diagnostically realistic radiopharmaceutical distributions, Nucl. Instrum. Meth. Phys. Res. A 299, 544-547.

Zubal I.G., Harrell C.R., Smith E.O., Rattner Z., Gindi G., Hoffer P.B. (1994) Computerized threedimensional segmented human anatomy, Med. Phys. 21, 299-302.

Zubal I.G., Harrell C.R., Smith E.O., Smith A.L. (1995) Two dedicated software, voxel-based, anthropomorphic (torso and head) phantoms, in: Voxel phantom development, 6 and 7 July 1995, Chilton, UK (P.J. Dimbylow, Ed.) pp. 105-111. 